\title{
FORMULATION DEVELOPMENT AND CHARACTERISATION OF MECLIZINE HYDROCHLORIDE FAST DISSOLVING TABLETS USING SOLID DISPERSION TECHNIQUE
}

\section{PRASHANT BHIDE*, REESHWA NACHINOLKAR}

Department of Pharmaceutics, Goa College of Pharmacy, $18^{\text {th }}$ June Road, Panaji-Goa, India Email: pjbhide_2000@yahoo.com

Received: 06 Mar 2018, Revised and Accepted: 06 Jun 2018

\section{ABSTRACT}

Objective: The aim of the present investigation was to design and evaluate fast dissolving tablet (FDT) for the oral delivery containing solid dispersion of meclizine (MCZ) hydrochloride, an antiemetic drug.

Methods: The solubility of meclizine was increased by preparing solid dispersions using mannitol as a carrier by fusion method. The prepared solid dispersion, was subjected for in vitro drug release, percent practical yield, drug content, infrared spectroscopy (IR), differential scanning calorimetry (DSC), scanning electron microscopy (SEM). Optimized solid dispersion was incorporated to prepare fast dissolving tablets. Preformulation studies were carried out on tablet blends. The prepared solid dispersion, as well as pure drug fast dissolving tablets, was evaluated for drug content, weight variation, hardness, friability, in vitro drug release, wetting time, disintegration time, water absorption ratio, in vitro dispersion time.

Results: Meclizine pure drug, solid dispersions formulations SD1, SD3 and SD5 showed 12.8, 31.68, 38.92 and 53.28\% cumulative drug release in phosphate buffer pH 6.8 after 60 min, respectively. Thus faster dissolution rate was exhibited by the solid dispersion containing 1:5 (w/w) ratio of meclizine: mannitol. Percent cumulative drug release for control and solid dispersion tablets after 60 min in phosphate buffer pH 6.8 was 92.04 and 98.2\% respectively. The release of drug meclizine from best formulation SD5 FDT was found to be faster than pure drug FDT.

Conclusion: Fast dissolving tablet of optimized solid dispersion showed better in vitro dissolution result then FDT of pure drug at the end of one hour.

Keywords: Meclizine hydrochloride, Fast dissolving tablets, Solid dispersion, Mannitol, Fusion

(C) 2018 The Authors. Published by Innovare Academic Sciences Pvt Ltd. This is an open access article under the CC BY license (http://creativecommons.org/licenses/by/4.0/) DOI: http://dx.doi.org/10.22159/ijap.2018v10i4.26493

\section{INTRODUCTION}

Solubility is an important physicochemical factor affecting absorption of the drug and its therapeutic effectiveness. Formulation development scientists are focusing on the development of oral dosage forms of poor aqueous solubility drugs through various solubility enhancing approaches. Among these approaches, preparation of solid dispersion is one of the widely used approaches to enhance the solubility and dissolution rate of poorly watersoluble drugs. Solid dispersions are defined as molecular dispersions of drugs in a polymer in solid form [1, 2].

Solid dispersions of fenofibrate were prepared using PEG 6000, poloxamer 407 and a mixture of polyethylene glycol 6000 (PEG 6000) and poloxamer 407 [3]. The solid dispersion of terbinafine $\mathrm{HCl}$ was prepared with PEG 6000 and mannitol to increase water solubility [4]. Solid dispersions of carvedilol with polyvinyl pyrrolidone (PVP K30) were prepared to improve solubility [5].

The present study is aimed to formulate and develop meclizine hydrochloride (MCZ) fast dissolving tablets of using solid dispersion method to improve the solubility and dissolution rate. MCZ is a firstgeneration antihistamine acting as $\mathrm{H}_{1}$ receptor antagonist and practically insoluble in water. MCZ is widely used in the treatment of motion sickness, but due to poor water solubility has delayed the onset of action [6]. To overcome this problem, this drug is selected for the present study and hence find advantageous to pediatric and geriatric patients who generally show the problem in swallowing.

The solid dispersion of MCZ was prepared by the solvent evaporation method using polyethylene glycol 4000 and 6000 as a carrier [7]. MCZ orodispersible tablets were prepared by using direct compression method [8]. MCZ fast dissolving tablets using sublimation method were prepared to enhance the dissolution rate [9].

Fast dissolving tablet (FDT) is defined as "a solid dosage form containing a medicinal substance or active ingredient which disintegrates rapidly usually within a matter of seconds when placed upon the tongue. Hoon Jeong, et al. reviewed that the different material properties for making fast dissolving tablets by a compression Method. Fast dissolving tablets (FDTs) are prepared by several different methods including crystalline transition, phase transition, sublimation, spray drying, and direct compression [10]. The goal of the present investigation was to design and evaluate fast dissolving tablet for the oral delivery containing the solid dispersion of water-insoluble antiemetic drug-meclizine with an aim to increase its solubility and dissolution rate. This is an novel approach that uses a mannitol as a carrier to prepare sustained release solid dispersion in different ratio.

\section{MATERIALS AND METHODS}

Materials

Meclizine Hydrochloride was obtained from Symed Labs Limited, Hyderabad, Telangana, India and mannitol from Amisha Chemicals, Ahmedabad, India as a gift sample. crospovidone and magnesium stearate were bought from Signet chemical Pvt. Ltd., Mumbai, India, spray dried lactose from Pfizer Ltd., Goa, India and purified talc from West coast laboratories, Mumbai, India. All reagents used were of analytical grade.

\section{Methodology}

Preparation of calibration curve of meclizine in water, $0.1 \mathrm{~N} \mathrm{HCl}$, and phosphate buffer $\mathrm{pH} 6.8$

A standard stock solution containing $100 \mu \mathrm{g} / \mathrm{ml}$ was prepared in methanol. From the working standard solution concentration of 2$20 \mu \mathrm{g} / \mathrm{ml}$ were prepared by dilution with water, $0.1 \mathrm{~N} \mathrm{HCl}$ and phosphate buffer $\mathrm{pH}$ 6.8. The calibration curve for MCZ was plotted on concentration v/s absorbance at $232 \mathrm{~nm}$ on Perkin Elmer Lambda 25 UV/VIS Spectrometer. Regression analysis was performed and MCZ concentration in the tablet was determined. 
Compatibility studies between the drug and excipients by IR spectroscopy

The infrared absorption spectrum was obtained by preparing a simple physical mixture of the drug and the carrier/excipient in 1:1 $(\mathrm{w} / \mathrm{w})$ ratio. The mixture was then placed on the stage of the instrument and scanned by the passage of an IR beam through it. The spectra were scanned over a frequency range $4000-600 \mathrm{~cm}^{-1}[2]$.

\section{Preparation of solid dispersions}

Solid dispersions were prepared with drug and polymers by fusion method. The polymer was used in a ratio of 1:1, 1:3 and 1:5 w/w of drug: polymer. Accurately weighed amount of carrier was melted in a porcelain dish at $80-85{ }^{\circ} \mathrm{C}$ and to this calculated amount of meclizine was added with thorough mixing for 1-2 min followed by quick cooling. The dried mass was pulverized, passed through 40 mesh sieve and stored in a desiccator [2].

\section{Evaluation of meclizine solid dispersions}

\section{Physical appearance}

All the batches of meclizine Solid dispersions were evaluated for color and appearance.

\section{Solubility studies}

The solubility studies of prepared solid dispersions were performed in $0.1 \mathrm{~N} \mathrm{HCl}$, distilled water, and phosphate buffer $\mathrm{pH}$ 7.4. An excess amount of preparation was weighed and transferred into the conical flasks which contain $10 \mathrm{ml}$ of media. The content in conical flask was sonicated for $2 \mathrm{~h}$ at room temperature, thereafter the samples were placed on a Remi ${ }^{\circledR}$ make orbital shaker, agitated at room temperature for $48 \mathrm{~h}$. Finally, the suspensions were filtered through a membrane filter paper, suitably diluted and analyzed spectrophotometrically at $232 \mathrm{~nm}$ [7].

\section{DSC analysis}

The thermal behavior of the prepared solid dispersions of meclizine was studied using differential scanning calorimetry (DSC). 3-4 mg of samples were weighed into aluminum pan and sealed with the lid having a pinhole in the center. Sealed pan-lid was then loaded on DSC instrument and heated from $0{ }^{\circ} \mathrm{C}$ to $300^{\circ} \mathrm{C}$ at a heating rate of $10^{\circ} \mathrm{C} / \mathrm{min}$. Nitrogen was used as the purge gas for the instrument [7].

\section{SEM studies}

The solid dispersions were evaluated for their physical structure and to study changes in the surface topography of the drug particles by scanning electron microscopy (SEM) technique [7].

\section{Percent practical yield}

Percent practical yield was calculated to know about percent yield or efficiency of the any method thus it helps in selection of appropriate method of production [9]. Solid dispersions were collected and weighed to determine practical yield (PY) from the following equation:

$$
\mathrm{PY}(\%)=\left[\frac{\text { practical mass }(\mathrm{Sd})}{\text { theoretical mass (drug + carrier) }}\right] \times 100
$$

\section{Preparation of FDT}

The fast dissolving tablets (FDTs) were prepared for selected solid dispersion preparations i.e., SD5, as given in table 1 . The solid dispersion powder equivalent to $25 \mathrm{mg}$ of MCZ, crospovidone and other excipients were passed through a mesh no 60 . The powdered solid dispersion was mixed with crospovidone. Then spray-dried lactose was added and mixed in a poly bag for 5-10 min. The blend was then lubricated with purified talc and magnesium stearate for another $5 \mathrm{~min}$. The blend was then subjected to preformulation studies. The resultant mixture was directly compressed into tablets using 10 station rotary tableting machine make Shakti ${ }^{\circledR}$ [9].

Table 1: Composition of meclizine and control fast dissolving tablet

\begin{tabular}{lll}
\hline Formulation code & Ingredients (in mg) & Control \\
\cline { 2 - 3 } & SD 5 & - \\
\hline MCZ solid dispersion equivalent to 25 mg MCZ & 125 & 25 \\
Pure meclizine & - & 5 \\
Crosspovidone (5\%) & 10 & 65 \\
Spray dried lactose & 60 & 2 \\
Magnesium stearate (1\%) & 2 & 3 \\
Purified talc (2\%) & 3 & 100 \\
Total amount (g) & 200 & \\
\hline
\end{tabular}

\section{Preformulation tests for tablet blend}

Bulk density $\left(D_{b}\right)$ was expressed in $\mathrm{g} / \mathrm{ml}$ and is given by

$$
\mathrm{Db}=\mathrm{M} / \mathrm{Vb}
$$

Where, $\mathrm{M}$ is the mass of powder and $\mathrm{V}_{\mathrm{b}}$ is the bulk volume of the powder [11].

Tapped density $\left(\mathbf{D}_{\mathbf{t}}\right)$ was expressed in $\mathrm{g} / \mathrm{ml}$ and is given by

$$
\mathrm{Dt}=\mathrm{M} / \mathrm{Vt}
$$

Where, $\mathrm{M}$ is the mass of powder and $\mathrm{V}_{\mathrm{t}}$ is the tapped volume of the powder [11].

\section{Angle of repose (q)}

$$
\mathrm{q}=\tan -1(\mathrm{~h} / \mathrm{r})
$$

Where, $\mathrm{q}$ is the angle of repose, $\mathrm{h}$ is the height in $\mathrm{cm}$ and $\mathrm{r}$ is the radius in $\mathrm{cm}$ [11].

Carr's index (or) \% compressibility was expressed in percentage and is given below

$$
\mathrm{I}=\frac{\mathrm{Dt}-\mathrm{Db}}{\mathrm{Dt}} \times 100
$$

Where, $D_{t}$ is the tapped density of the powder and $D_{b}$ is the bulk density of the powder [12].

\section{Hausner ratio}

$$
\text { Hausner ratio }=\frac{\mathrm{Dt}}{\mathrm{Db}}
$$

Where, $D_{t}$ is the tapped density and $D_{b}$ is the bulk density [13].

\section{Evaluation of fast dissolving tablets}

Weight variation, hardness, friability (F). These tests were performed on prepared tablets $[11,14]$.

\section{Wetting time}

A piece of tissue paper folded double was placed in a Petri plate (internal diameter is $6.5 \mathrm{~cm}$ ) containing $6 \mathrm{ml}$ of water. The tablet was placed on the paper and the time for complete wetting of the tablet was measured in seconds. The method was slightly modified by maintaining water at $37^{\circ} \mathrm{C}$ [15].

\section{In vitro drug release}

The release of the drug in vitro was determined by estimating the dissolution profile [9]. 


\section{Dissolution test}

USP 2 (Paddle) apparatus at $50 \mathrm{rpm}$ was used with $900 \mathrm{ml}$ phosphate buffer ( $\mathrm{pH}$ 6.8) as a dissolution medium [11]

\section{Drug content}

Ten tablets were crushed, and $100 \mathrm{mg}$ of the powder was accurately weighed and transferred to a $100 \mathrm{ml}$ volumetric flask. About $50 \mathrm{ml}$ of phosphate buffer pH 6.8 was added to the volumetric flask and allowed to stand for 6-8 $\mathrm{h}$ with intermittent shaking. The solution was then filtered and volume was made up to $100 \mathrm{ml}$ with buffer, and drug content was determined by UV-visible spectrophotometer at $232 \mathrm{~nm}$ [9].

\section{Rapid disintegrating property}

To evaluate the tablets for their rapid disintegration properties, following tests were carried out [9].

\section{Disintegration test}

A Petri dish (10 $\mathrm{cm}$ dia.) was filled with $10 \mathrm{ml}$ of water. The tablet was carefully placed at the center of Petri dish and the time for the tablet to completely disintegrate into fine particles was noted [16].

\section{Water absorption ratio}

A piece of tissue paper folded twice was placed in a small Petri dish containing $6 \mathrm{ml}$ of water. A tablet was put on the paper and the time required for complete wetting was measured. The wetted tablet was then weighed. Water absorption ratio, R, was determined using following equation,

$$
\mathrm{R}=10(\mathrm{Wa} / \mathrm{Wb})
$$

Where, $\mathrm{W}_{\mathrm{b}}$ is the weight of tablet before water absorption and $\mathrm{W}_{\mathrm{a}}$ is the weight of tablet after water absorption [9].

\section{In vitro dispersion time}

Tablet was added to $10 \mathrm{ml}$ of phosphate buffer solution, $\mathrm{pH} 6.8$ at $37 \pm 0.5^{\circ} \mathrm{C}$. The time required for complete dispersion of a tablet was measured [9].

\section{RESULTS AND DISCUSSION}

\section{Physical appearance and solubility}

An off-white powder granular product in appearance was obtained.

\section{Percent practical yield}

The percent practical yield obtained for formulation SD1, SD3 and SD5 were $90.12,94.06$ and $94.23 \%$ respectively.

\section{Standard calibration curve of meclizine}

Standard plot of drug concentrations from 0 to $20 \mu \mathrm{g} / \mathrm{ml}$ was obtained. The straight line equations and regression coefficients obtained for $0.1 \mathrm{~N} \mathrm{HCl}$, water and buffer $\mathrm{pH} 6.8$ are $\mathrm{y}=$ $0.0433 x+0.0265, R^{2}=0.9939 ; y=0.0586 x+0.0029, R^{2}=0.9943$ and $y=0.0618 x-0.0264, R^{2}=0.9969$, respectively.

Compatibility studies between meclizine and excipients by IR spectroscopy

No interaction was observed when meclizine and mannitol 1:1 w/w mixture was tested.

\section{Solubility studies}

Solubility measurements of meclizine pure drug and its solid dispersions are tabulated in table 2 . From the solubility studies of the prepared solid dispersions in different media, it was found that as the increase in $\mathrm{pH}$ of the media increased the solubility i.e. meclizine showed superior solubility in phosphate buffer $\mathrm{pH} 6.8$ when compared with others.

Table 2: Solubility measurements of meclizine pure drug and its solid dispersions

\begin{tabular}{llll}
\hline Formulation code & \multicolumn{2}{l}{ Solubility $\mathbf{( m g / m l ) \pm S D *}$} & Buffer $\mathbf{p H ~ 6 . 8}$ \\
\cline { 2 - 4 } & $\mathbf{0 . 1} \mathbf{~ N ~ H C l}$ & Distilled water & $0.978 \pm 0.32$ \\
\hline Pure drug & $0.322 \pm 0.21$ & $0.964 \pm 0.15$ & $1.429 \pm 0.33$ \\
SD1 & $0.508 \pm 0.19$ & $1.121 \pm 0.22$ & $1.605 \pm 0.21$ \\
SD3 & $0.611 \pm 0.22$ & $1.321 \pm 0.23$ & $1.691 \pm 0.27$ \\
SD5 & $0.698 \pm 0.12$ & $1.480 \pm 0.11$ & \\
\hline
\end{tabular}

*mean \pm standard deviation (SD), $\mathrm{n}=3$

\section{DSC and SEM studies}

The DSC thermogram of meclizine showed a sharp endothermic peak at $216.32{ }^{\circ} \mathrm{C}$ (fig. $1 \mathrm{a}$ ) corresponding to its melting point, indicating its crystalline nature. The DSC thermogram of solid dispersion SD5 showed a sharp endothermic peak at $167.22^{\circ} \mathrm{C}$, corresponding to the melting point of mannitol (fig. 1b). The absence of the endothermic peak of meclizine in the thermograms suggests that meclizine has probably solubilised in the melted mannitol. Due to the absence of the endothermic peak of meclizine in the solid dispersions, SD5 studies reveal that drug was no longer present in crystalline form and probably molecularly dispersed in amorphous form inside the polymeric matrix of mannitol.

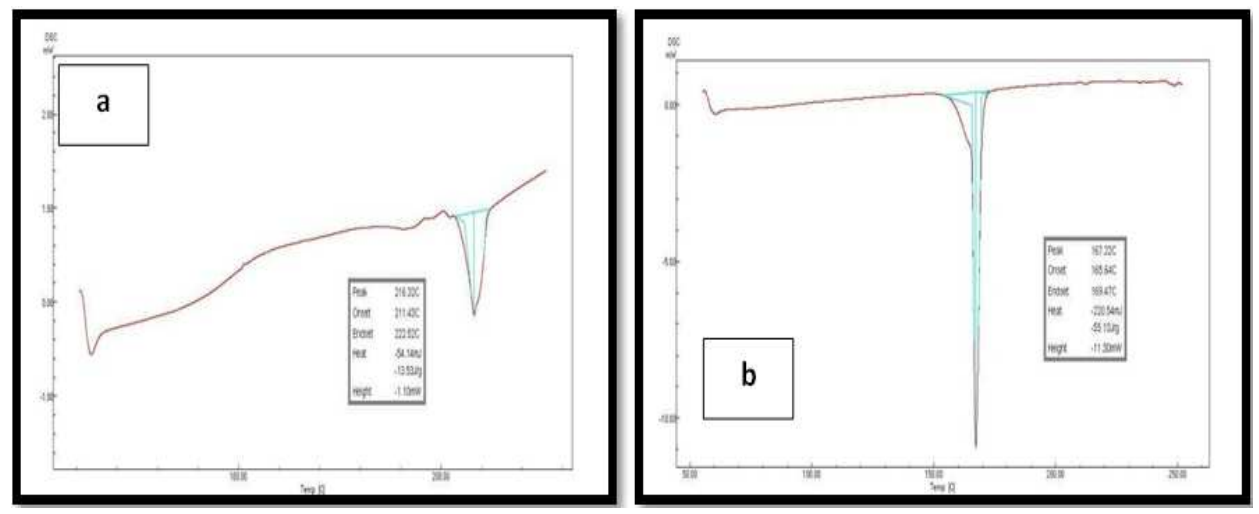

Fig. 1: DSC thermogram of meclizine (a) and solid dispersion SD5 (b) 
The MCZ crystals are usually fine needles with smooth surfaces, partially agglomerated in bundles. The SEM result shows that in the case of solid dispersion of MCZ particles were in almost amorphous form, which indicates a reduction in particle size. The photomicrographs (fig. 2) of the solid dispersion show that MCZ might have dispersed in the carrier. These observations provide the evidence of solid dispersion formation.

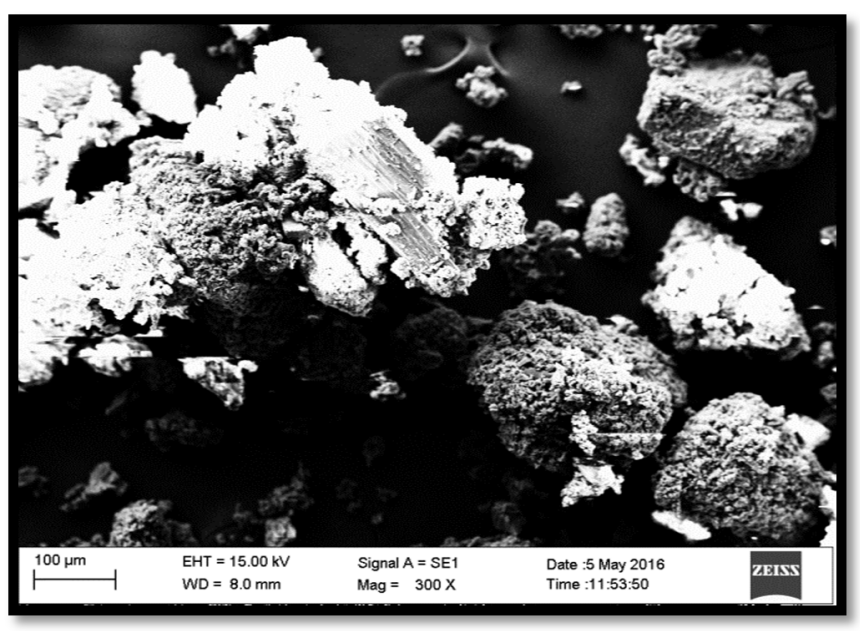

Fig. 2: SEM images of solid dispersion SD5

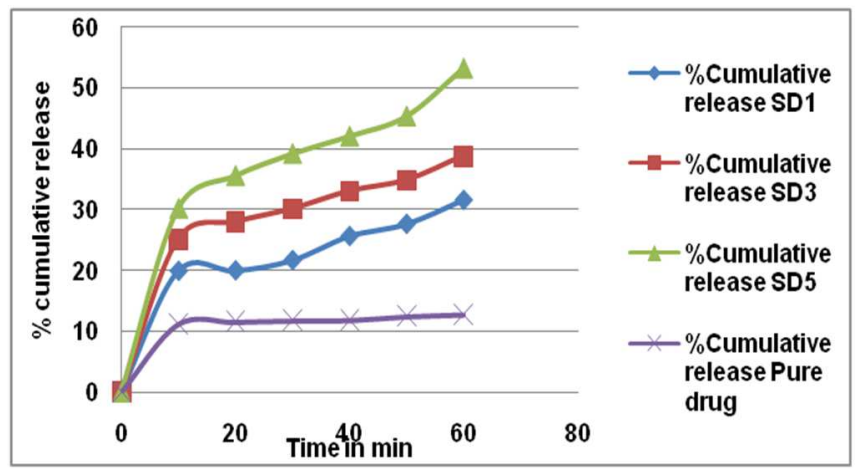

Fig. 3: In vitro drug release profile of meclizine pure drug, solid dispersion SD1, SD3 and SD5 (n=3)

\section{Dissolution profile of meclizine pure drug and solid dispersion}

Meclizine pure drug and SD1, SD3 and SD5 formulations showed $12.8,31.68,38.92$ and $53.28 \%$ cumulative drug release in phosphate buffer pH 6.8 after $60 \mathrm{~min}$, respectively as shown in fig. 3 .

\section{Statistical analysis}

The in vitro drug release data of the selected solid dispersions-SD1, SD3 and SD5 were treated to first order, Higuchi diffusion plot [17] and Peppa's exponential. The $\mathrm{R}$ values for first-order plots were significantly higher as compared to zero order plots which indicate that all the formulations best fitted in first order kinetics and poorly fitted in zero order kinetics. The first-order plot was found to be fairly linear indicating that the drug release followed first order kinetics, with solid dispersion SD5 showing the highest $\mathrm{R}^{2}$ value of 0.991. Similarly, the data was treated according to Higuchi's diffusion equation. The best fit with higher correlation was found with the Higuchi's equation for most of the formulations with the highest correlation coefficient $\left(\mathrm{R}^{2}=0.969\right)$ for solid dispersion SD3. The result indicated that all formulations exhibited diffusion mechanism in drug release. Further, the data was subjected to Peppa's model where R-value revealed that the Peppa's model best fitted in all dissolution profiles. Peppa's exponential plot gave slope values lesser than 0.5 for solid dispersions SD1 (0.254), SD3 (0.230) and SD5 (0.288) indicating that the drug release followed Fick's Law of diffusion. Thus the drug release from solid dispersions is diffusion controlled and followed first order kinetics.

\section{Preformulation tests of fast dissolving tablets}

Results of the bulk density, tap density, angle of repose, Carr's index and Hausner ratio are given in table 3 . The resultant bulk and tapped density indicated good to fair flowability. The angle of repose results indicates a good and passable flow of powdered mixture. Carr's index or \% compressibility indicates that resultant the powdered mixture posses' good compressibility. Hausner's ratio was found to be less than 1.25 which indicates better flow properties during tableting process.

Table 3: Preformulation parameters for solid dispersion SD5 and control tablets

\begin{tabular}{|c|c|c|c|c|c|}
\hline Formulation & $\begin{array}{l}\text { Bulk density } \\
\left(\mathrm{gm} / \mathrm{cc}^{3}\right)\end{array}$ & $\begin{array}{l}\text { Tap density } \\
\left(\mathrm{gm} / \mathrm{cc}^{3}\right)\end{array}$ & Angle of repose $\left({ }^{\circ}\right)$ & Carr's index (\%) & Hausner ratio \\
\hline SD5 & $0.331 \pm 1.66$ & $0.387 \pm 1.54$ & $28.46 \pm 1.72$ & $14.47 \pm 1.58$ & $1.160 \pm 1.61$ \\
\hline CONTROL & $0.338 \pm 1.32$ & $0.396 \pm 1.43$ & $30.10 \pm 1.26$ & $14.64 \pm 1.66$ & $1.171 \pm 1.63$ \\
\hline
\end{tabular}

*mean \pm SD, $\mathrm{n}=3$ 
Table 4: Quality control tests for solid dispersion SD5 and control tablets

\begin{tabular}{llll}
\hline Formulation & Weight variation $(\mathbf{m g})^{*}$ & Hardness $\left.\mathbf{( K g} / \mathbf{c m}^{2}\right)^{* *}$ & Friability (\%)+ \\
\hline SD5 & $201.68 \pm 1.31$ & $3.0 \pm 0.23$ & $0.34 \pm 0.001$ \\
CONTROL & $100.18 \pm 1.27$ & $3.0 \pm 0.18$ & $0.25 \pm 0.001$ \\
\hline
\end{tabular}

*All values represent mean \pm standard deviation, $\mathrm{n}=20$; **All values represent mean \pm standard deviation, $\mathrm{n}=6$; + All values represent mean \pm standard deviation, $\mathrm{n}=3$; ++All values represent mean \pm standard deviation, $\mathrm{n}=3$.

\section{Evaluation of meclizine solid dispersion incorporated fast dissolving tablets}

The results of weight variation, hardness, friability and wetting time are given in table 4 . The tablets were found to comply with pharmacopoeial requirements. Fast dissolving tablet of solid dispersion SD5 showed faster wetting then controlled fast dissolving tablet $[16,18,19]$.

\section{Dissolution studies}

Percent cumulative drug release for control and solid dispersion tablets after 60 min in phosphate buffer pH 6.8 was 92.04 and $98.2 \%$ respectively. The release of meclizine from SD5 FDT was found to be faster than pure drug FDT.

The overall increase in the dissolution performance of the optimized formulation was described in terms of dissolution parameters Initial dissolution rate (IDR), Dissolution efficiency (DE), Relative dissolution rate (RDR) and when compared with control tablets and all the above parameters were increased in case of SD5 FDT formulation, as seen in table 5 [20].

\section{Drug content}

Drug content of the solid dispersions tablet was found to be $98.3 \%$ and that of control tablet was found to be $99.01 \%$. Both tablets showed the presence of high drug content.

\section{Rapidly disintegrating properties}

Disintegration time was found to be $25 \mathrm{sec}$ for FDT of solid dispersion SD5 and 19 sec for control FDT. Water absorption ratio was found to be 154 for FDT of solid dispersion SD5 and 146 for control FDT. Solid dispersion FDT showed faster disintegration and higher water absorption ratio then control tablet [19].

Table 5: Dissolution parameters of MCZ SD5 and control tablets

\begin{tabular}{|c|c|c|c|c|}
\hline Formulation code & Q 20 & IDR (\%/min) & DE & RDR \\
\hline SD5 & $97.56 \pm 1.46$ & $4.878 \pm 1.21$ & $62.37 \pm 1.66$ & $2.56 \pm 1.23$ \\
\hline Control & $38.0 \pm 1.61$ & $1.26 \pm 1.55$ & $44.53 \pm 1.12$ & \\
\hline
\end{tabular}

IDR: Initial dissolution rate, DE: Disolution efficiency, RDR: Relative dissolution rate; mean $\pm S D, n=3$

\section{CONCLUSION}

The dissolution rate of meclizine from solid dispersion was significantly higher than that of pure drug. The general trend indicated that there was an increase in dissolution rate for solid dispersion in the following order of SD 1:5>SD 1:3>SD 1:1. IR studies indicated that no chemical interaction between drug and carrier/excipient took place during the preparation of the solid dispersion of meclizine. Aqueous solubility studies revealed that solid dispersions SD5 posses higher solubility in phosphate buffer $\mathrm{pH}$ 6.8. The in vitro release of meclizine from solid dispersions SD1, SD3, SD5 were found to be faster than the pure drug itself. The cumulative percent drug released after $60 \mathrm{~min}$ was found to be highest in SD5 followed by SD3 and SD1. The prepared fast dissolving tablets blend showed good pre-compression properties i.e. the angle of repose, bulk density, tapped density, Carr's index and Hausner ratios and the results were within the limits. The control, as well as SD5 fast dissolving tablets, showed weight variation, hardness, friability, wetting time, disintegration time, water absorption ratio results complying with pharmacopoeial limits. The release of meclizine from SD5 fast dissolving tablets was found to be faster than pure drug FDT.

\section{ACKNOWLEDGMENT}

The authors are thankful to Symed Labs Limited, Hyderabad, Telangana, India and Amisha Chemicals, Ahmedabad, India for gift sample and Govt. of Goa for providing lab facilities.

\section{AUTHORS CONTRIBUTIONS}

All the author have contributed equally

\section{CONFLICT OF INTERESTS}

Declared none

\section{REFERENCES}

1. Saharan VA, Kukkar V, Kataria M, Gera M, Choudhury PK. Dissolution enhancement of drugs, Part I: Technologies and effect of carriers. Int J Health Res 2009;2:107-24.
2. Dhirendra K, Lewis S, Udupa N, Atin K. Solid dispersion: a review. Pak J Pharm Sci 2009;22:234-46.

3. Patel T, Patel LD, Patel T, Makwana S, Patel T. Enhancement of dissolution of Fenofibrate by solid dispersion technique. Int J Res Pharm Sci 2010;1:127-32.

4. Subhashis D, Gampa VK, SV Satyanarayana. Preparation and evaluation of solid dispersion of terbinafine hydrochloride. Asian J Pharm Tech 2013;3:9-15.

5. Sharma A, Jain CP. Preparation and characterization of solid dispersions of carvedilol with PVP K30. Res Pharm Sci 2010;5:49-6.

6. Martindale: the complete drug reference. $35^{\text {th }}$ ed. Pharmaceutical Press; 2007.

7. Daravath B, Tadikonda RR. Formulation and evaluation of meclizine hydrochloride fast dissolving tablets using solid dispersion method. Asian J Pharm Clin Res 2014;7:98-102.

8. Mowafaq M Ghareeb, Twana M, Mohammedways G, Mohammedways. Development and evaluation of orodispersible tablets of meclizine hydrochloride. Int J Pharm Sci Res 2012;3:5101-10.

9. Vemula SK, Katkum R. Development and physical characterization of meclizine hydrochloride solid dispersions by using polyethylene glycol 8000. Sci Technol Arts Res J 2014;3:48-2.

10. Jeong SH, Takaishi Y, Yourong F, Park K. Material properties for making fast dissolving tablets by a compression method. J Mater Chem 2008;18:3527-35.

11. USP36 NF31, United states pharmacopoeial convention; 2013.

12. Swarbrick J, Boylan J. Encyclopedia of pharmaceutical technology. $2^{\text {nd }}$ ed. 2002. p. 642.

13. Marshall K, Lachman L, Liberman H, Kanig J. The theory and practice of industrial pharmacy. $3^{\text {rd }}$ Ed. Varghese publishing house, India; 1987. p. 66-99,293-345.

14. Indian Pharmacopoeia. The Indian pharmacopoeia commission; 2014.

15. Washburn EW. The dynamics of capillary flow. Phys Rev 1921;17:273.

16. Ved Prakash, Maan S, Deepika, Yadav SK, Hemlata, Jogpal V. Fast disintegrating tablets: opportunity in drug delivery system. J Adv Pharm Technol Res 2011;2:223-35. 
17. Higuchi T. Mechanism of sustained medication, Theoretical analysis of rate of release of solid drugs dispersed in solid matrices. J Pharm Sci 1963;84:1464-77.

18. CP Jain, PS Naruka. Formulation and evaluation of fast dissolving tablets of valsartan. Int J Pharm Pharm Sci 2009;1:219-26.
19. Patel B, Patel D, Parmar R, Patel C, Serasiya T, Sanja SD. Development and in vitro evaluation of fast dissolving tablets of glipizide. Int J Pharm Pharm Sci 2009;1:145-50.

20. Daravath B, Tadikonda RR. Formulation and development of meclizine hydrochloride fast dissolving tablets using solid dispersion method. Asian J Pharm Clin Res 2014;7:98-102. 